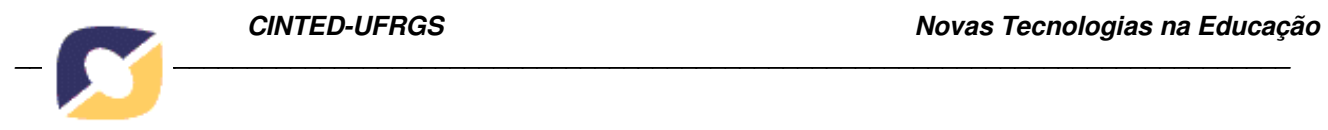

\title{
O autor e seu personagem no MMORPG sob a ótica do interacionismo sócio- discursivo
}

\author{
Chislene Moreira Cardoso - UNISINOS - xlenemc@yahoo.com.br \\ Dinorá Moraes de Fraga - UNISINOS - dinoraf@ unisinos.br
}

\section{Resumo}

As novas tecnologias presentes na prática social dos adolescentes e jovens contemporâneos exigem dos professores uma reflexão a respeito dos currículos que não contemplam recursos digitais. Partindo dessas reflexões, apresentaremos uma proposta que visa fornecer um suporte teórico para o professor que trabalha com narrativas em sala de aula. O presente artigo discute como se constitui um personagem e seu respectivo autor na ordem do expor e na ordem do narrar, à luz do Interacionismo Sócio-discursivo (ISD). Com base nas teorias visitadas, o professor poderá analisar os personagens construídos por seus alunos, ou autores, no Massive Multiplayer Online Playing Game (MMORPG) e apresentar-lhes as maneiras de elaborar um personagem completo, considerando os recursos de hipermídia que o ambiente digital pode lhes oferecer.

Palavras-chave: personagem, mmorpg, interacionismo sócio-discursivo.

\begin{abstract}
New technologies in the social practice of teenagers and young contemporaries require a reflection of the teachers about the curriculum not include digital resources. With these thoughts, we will present a proposal to provide a theoretical support for the teacher who works with narratives in the classroom. This article discusses how to constitute a character and its author in order of the expose and order of the narrate, in light of Sociodiscursive Interactionism (SDI). Based on the theories visited, the teacher can analyze the characters built by his students, or authors, in Massive Multiplayer Online Playing Game (MMORPG) and present them ways to produce a complete character, considering the resources of hypermedia that the digital environment can offer.
\end{abstract}

Keywords: character, mmorpg, socio-discursive interactionism

\section{Novas Tecnologias e Educação}

As novas tecnologias da informação ${ }^{1}$ e comunicação estão presentes no cotidiano do adolescente em muitos países e, também, no Brasil, como confirma o Instituto Brasileiro de Geografia e Estatística (IBGE), no último censo de 2005. A faixa etária que mais utilizou a internet corresponde aos adolescentes de 15 a 17 anos. 33,1\% dos meninos e 34,6\% das meninas haviam "navegado" na rede mundial nos últimos três meses que antecederam a pesquisa. Os números diminuem muito pouco em relação aos jovens de 18 ou 19 anos. $31,9 \%$ dos homens contra $33,9 \%$ das mulheres utilizaram a internet no mesmo período da pesquisa.

Com os projetos de inclusão digital do governo, e a inevitável presença das novas tecnologias na prática social dos cidadãos, o número de usuários da internet tende a aumentar. É compreensível que as novidades tecnológicas tragam um certo desconforto 
àqueles que não sabem utilizá-la adequadamente, e é por isso que, professores e alunos devem se preparar para fazer uso dessa tecnologia da maneira mais produtiva possível.

De acordo com os Parâmetros Curriculares Nacionais do Ensino Médio, parte II, as tecnologias de informações devem permear o currículo da escola, já que promovem a mais nova linguagem presente em nosso cotidiano e em nosso mundo do trabalho, a a linguagem digital. Ainda segundo os PCN's, cabe à escola esclarecer "as relações existentes, a indagação de suas fontes, a consciência de sua existência, o reconhecimento de suas possibilidades, e a democratização de seus usos".

Considerando as orientações aos professores propostas pelos PCN`s do Ensino Médio, que partem dos princípios definidos na Lei de Diretrizes e Bases (LDB), n. 9394, de 20 de Dezembro de 1996, percebemos a intenção e a ação de professores e pesquisadores ao adequarem ao currículo escolar às novas tecnologias que emergem da sociedade contemporânea.

Para reforçar o trabalho com as tecnologias digitais na educação, sugerimos a leitura dos artigos a seguir. O primeiro artigo, Tecnologia e educação: relações históricas, locais e mundializadas (GARCIA, 2005), apresenta um panorama histórico do processo de informatização na escola, partindo de uma perspectiva conceitual e filosófica a respeito de técnica e tecnologia. O artigo seguinte, Novas Tecnologias em Ambientes de Aprendizagem; Estimulando o Aprender a Aprender, Transformando o Currículo e Ações (FRANCO e LOPES, 2004), trata de experiências de aprendizagem por meio de uso cooperativo das tecnologias disponíveis na Internet. A proposta foi desenvolvida com professores e alunos da educação básica. O próximo, Tecnologias na escola: algumas experiências e possibilidades (DUTRA e LACERDA, 2003), discorre sobre algumas experiências em parceria com escolas públicas, e também apresenta algumas possibilidades de uso das novas tecnologias na escola por meio de webfólio, fórum de discussão ou blog.

No que tange ao uso do MMORPG (Massive Multiplayer Online Role Playing Game), jogo online massivo para múltiplos jogadores de interpretação de papéis, ou simplesmente RPG online, em um ambiente educacional, propomos a leitura do artigo, Relato de uma experiência de Sistema Híbrido no Ensino Fundamental: Projeto Aulativa (LOPES et al, 2003), que trata da aplicação do MMORPG nas aulas de História e Geografia de turmas de Quinta e Sexta séries. O artigo, O RPG como instrumento pedagógico (AMARAL, 2006), nos mostra a aplicação do RPG de mesa, ou RPG tradicional, desenvolvido na disciplina de Física para turmas do Ensino Médio. Outro artigo, RPG: Uma abordagem empregando sistemas multiagentes (MACHADO et al, 2004), também trata da aplicação em aulas relacionadas à área de exatas. Este artigo sugere a construção de um RPG de mesa para ser trabalhado nas aulas de Matemática.

Acerca do trabalho com MMORPG nas disciplinas de Língua Portuguesa, gostaríamos de propor a leitura do artigo Jogo de RPG no ensino e aprendizagem de narrativas não-lineares (FRAGA e PEDROSO, 2006). Este artigo, propõe a construção de narrativas não-lineares a partir do MMORPG Priston Tale, e nossa proposta segue os preceitos adotados pelos autores.

A partir das leituras citadas, percebemos a preocupação de diversos pesquisadores com a nova realidade tecnológica presente em nosso cotidiano, no caso em questão, no contexto educacional. Além de observarmos também a preocupação recorrente dos pesquisadores em inserir o uso de jogos na prática educativa. $\mathrm{O}$ que nos faz pensar se realmente é possível utilizarmos os jogos em ambiente digital no processo de ensinoaprendizagem dos adolescentes. 
Para confirmar essa possibilidade, apresentamos uma proposta que visa fornecer um suporte teórico para o professor que trabalha com narrativas em sala de aula. O presente artigo discute como se constitui um personagem e seu respectivo autor na ordem do expor e na ordem do narrar à luz do Interacionismo Sócio-discursivo (ISD), proposto por Bronckart e outros pesquisadores, que considera as dimensões sociais e discursivas/textuais das ações humanas. Esta proposta segue os preceitos do interacionismo social, sob a perspectiva da psicologia social Vygotskiana e da sociologia de Habermas e de Ricoeur (Bronckart, 1999, p. 13), além dos estudos sobre gêneros textuais de Bakhtin.

Com base nas teorias visitadas, o professor poderá analisar os personagens construídos por seus alunos, ou autores, no MMORPG e apresentar-lhes as maneiras de elaborar um personagem completo, considerando os recursos de hipermídia que o ambiente digital pode lhes oferecer. Conforme Molina (2007), em sua dissertação, Análise das características narrativas e do ambiente digital dos jogos em rede: um estudo de caso do jogo Priston Tale, “os MMORPG's permitem criar personagens capazes de encontrar dentro do contexto estabelecido pelo jogo um espaço próprio, de múltiplas escolhas e variadas possibilidades".

\section{Reflexões em torno do Autor e do Personagem}

O personagem é criado por um autor, que neste momento pode ser denominado de jogador também, já que estamos tratando de jogos em ambientes digitais. $\mathrm{O}$ autor define as características de seu personagem. No MMORPG, o autor escolherá o grupo e a classe que o seu personagem ocupará no jogo. Essas escolhas incidem nas habilidades e limitações do personagem, pois a cada classe são atribuídas características previamente estabelecidas pela equipe de suporte.

Ao escolher o personagem e suas respectivas habilidades e limitações, o autor compreende que a narrativa será estruturada em torno dessas características, e terá que desenvolver a história dentro de suas possibilidades. Por exemplo, se um personagem não tem poderes mágicos, o autor tem noção de que não pode ficar invisível, a menos que, no decorrer do jogo, surja alguma fórmula que lhe dê esse poder. Isto seria coerente nesta narrativa. $\mathrm{O}$ autor sabe das habilidades e limitações de seu personagem, por isso direcionará a narrativa de acordo com as suas possibilidades, pois se não fizer isso, o jogo pode acabar pra seu personagem.

E é a partir destes aspectos de elaboração de uma narrativa, que estabelecemos o objeto de nosso estudo, a relação entre o autor e seu personagem em um ambiente de jogo digital. O nosso objetivo é apresentar ao professor de Língua Portuguesa do Ensino Médio, uma alternativa de trabalho, cujo foco é a construção de um personagem no MMORPG e, em seguida, desenvolver uma narrativa obedecendo as propostas apresentadas posteriormente.

A partir das atividades desenvolvidas, o professor analisará se o aluno apropriou-se dos elementos necessários para a construção de um personagem. Discorreremos sobre esses elementos a seguir, para que o professor possa se munir das armas que lhe possibilitarão verificar se o aluno apreendeu os pontos abordados para a construção de um personagem sob uma perspectiva bakhtiniana, que aponta a relação do autor com o seu personagem e, também, sob o ponto de vista de Bronckart, que apresenta o posicionamento enunciativo do autor no mundo discursivo. 


\section{Bakhtin}

Uma obra literária é considerada como uma resposta a outras obras, no plano do dialogismo de Bakhtin, isto é, a obra, tratada como um enunciado, é vista como um elo na cadeia da comunicação verbal e, por isso, dialoga com outras obras anteriores. A obra é resultado das leituras de obras já existentes, que se manifestarão na composição de uma ou mais obras. E essas obras, por conseguinte, manifestar-se-ão nas obras posteriores, estabelecendo, assim, um elo nessa cadeia de enunciados. Não há um enunciado que não seja resposta a outro enunciado.

Para uma melhor compreensão das idéias de Bakhtin, sugerimos a leitura do artigo, Dialogismo ou Polifonia (RECHDAN, 2003), que traz a análise de um artigo de opinião, sob a ótica de Bakhtin. Sugerimos também a leitura das Anotações sobre Bakhtin (DAVID, 2003), apresentadas nas aulas do Professor João Wanderley Geraldi. Este texto apresenta algumas das terminologias mais usadas por Bakhtin.

Retomando o assunto, ao construir sua obra, o autor determina a estrutura de seu objeto, no caso, o personagem. Cada elemento de sua obra, inclusive o personagem, também é visto como uma resposta do autor a outras obras anteriores. Portanto, cada particularidade, cada trejeito, cada acontecimento, cada sentimento de seu personagem é visto também como uma resposta a outra resposta, considerando que a construção do autor, ou seja, sua obra, seja um elo na cadeia da comunicação discursiva. No caso em questão, as características do personagem e as relações vão sendo estabelecidas durante o jogo com outros personagens. $\mathrm{O}$ personagem é resultado das representações do leitor acerca de outros personagens, anteriormente conhecidos. Este personagem pode ser semelhante ou oposta a outros e, mesmo assim, fará parte do elo, pois suas características se assemelham ou divergem de um referencial, ou seja, de outro personagem.

$\mathrm{Na}$ vida, ao contarmos uma história baseamo-nos em nossos conceitos e significações. Essas histórias são respostas inspiradas em nossos valores morais, éticos, estéticos, religiosos, dentre outros, que damos às manifestações anteriores. Para cada manifestação em particular, elaboramos uma resposta. Não há uma resposta única para todas as manifestações anteriores e passamos a vida dando respostas para cada manifestação que surge. Bakhtin prefere não conjeturar sobre esse assunto por ser um processo regido pela lei psicológica, que foge de sua alçada.

Agora, no que diz respeito aos valores estéticos, referente à arte literária, a história contada pelo autor baseia-se em idéias relacionadas à obra em si no plano da criação, e não em idéias e sentido do autor. A obra não é um confessionário do autor. $O$ autor não comenta na obra sobre suas dificuldades no processo da escrita. A obra deve ser uma resposta única, uma unidade, um todo acabado, que responde as obras anteriores.

Se verificarmos uma resposta do autor para cada manifestação, não temos o todo do personagem, pois o autor não conseguiria terminar a sua obra. Nesse primeiro caso, temos um indivíduo do mundo real, que Bakhtin classifica como: autor-pessoa. A obra desse autor se limita a retratar suas idéias e sentido. Apresenta um valor biográfico, mas não um valor estético, no âmbito literário. O personagem representa a voz do autor.

Quando esta situação ocorre, o personagem corresponde ao autor-pessoa no momento em que observamos a voz do autor presente em seu objeto. A criação de aspectos físicos, sociais e psicológicos reflete os conceitos e significações do autor e não do personagem em si. Esse personagem pode seguir duas direções. Pode ser autobiográfico, quando a voz do autor posiciona-se de forma direta na voz do personagem, ou pode não ser 
autobiográfico, quando a voz do autor é percebida de forma indireta. Este tipo de personagem não alcança a sua completude.

Aqui, a voz social do autor predomina sobre a voz do personagem, pois o autorpessoa apossa-se do objeto de sua obra. No que tange ao MMORPG, facilmente reconheceremos o autor ou jogador, que construiu um determinado personagem, pois sua voz sobrepõe-se a voz do personagem. Suas idéias, suas significações, suas vivências, impregnados de seus valores e, ainda, de sua maneira de se expressar, estarão presentes na voz do personagem. Se o autor constrói um personagem que se ambienta no período medieval e transporta suas opiniões instituídas sobre um assunto contemporâneo, por exemplo, as células-tronco, perceberemos uma incoerência na voz do personagem à época a que lhe foi atribuída, a idade média. Dessa forma, verificamos que o autor não alcançou a completude do personagem, pois a voz desse apenas reflete uma resposta do autor a uma manifestação em particular. O personagem está totalmente vinculado ao autor, pois representa sua voz social.

Um outro caso de autor é denominado por Bakhtin como o autor-contemplador. Esse tipo de autor carrega características do autor-pessoa e do autor-criador. Seu personagem é estruturado com base em suas vontades e emoções, fechadas em sua própria obra, mas também reflete os valores do autor, representa a voz social de quem a construiu. $\mathrm{O}$ autor-contemplador alcança um processo criativo, mas recorre a sua vivência para explicar acontecimentos de seu personagem, que não encontram resposta no todo da obra. O autor, ao mesmo tempo em que coloca a sua voz no personagem, vê a necessidade de se colocar fora do personagem, numa espécie de contemplação, para que o objeto de sua obra não se limite a expressar as suas vivências.

Nesse caso, o personagem é fruto do autor-contemplador. Ao mesmo tempo em que o personagem segue as suas próprias vontades e emoções, ela também obriga o autor a recorrer a sua experiência de vida para ser convincente. Ao mesmo tempo em que responde ao lado estético, no âmbito da arte literária, também apresenta as idéias e sentidos sob uma perspectiva biográfica e, por isso, o personagem do autor-contemplador não se torna completa em si. O todo do personagem não é alcançado.

A respeito do MMORPG, observaremos um personagem que em alguns momentos assume o domínio sobre o autor, mas que, em outros momentos, a voz do autor sobrepõe-se à voz do personagem. Perceberemos a presença de um personagem que dá seus primeiros passos para desvincular-se do autor ou jogador. Ora apresenta vontade própria, ora reflete as vontades de seu autor. $\mathrm{O}$ autor-contemplador cria um personagem que pretende ser autônomo, mas que, em algumas situações, precisa recorrer à sua vivência para justificar alguns acontecimentos de seu personagem. Há um misto de criação e autobiografia e, devido ao vínculo ainda existente, o personagem não alcança sua completude.

No terceiro e último caso, o autor consegue dar uma resposta única a todas as manifestações e, por este motivo, temos o todo do personagem, um personagem completo e acabado, presente em uma obra completa e acabada, que é a resposta única do autor. Bakhtin o define como autor-criador. $\mathrm{O}$ autor-criador reflete as idéias do personagem e não as suas. Nesse caso, a obra apresenta um valor estético, do ponto de vista da arte literária.

Enquanto o autor-pessoa descreve suas vivências do mundo real, o autor-criador, descreve as vivências do personagem no mundo da ficção, e aqui percebemos o processo de criação mais elaborado. "As personagens criadas se desligam do processo que as criou e começam a levar uma vida autônoma no mundo" (Bakhtin, 2003, p. 6). Esse é o autor que pretendemos desenvolver com os alunos. O autor apto à criação de um personagem 
completo. $\mathrm{O}$ autor que desenvolva suas competências e habilidades na produção estética, no plano literário, e não se limite a narrar os acontecimentos de sua vida, mas que seja "trangrediente" (Bakhtin, 2003, p. 7), ou seja, que ultrapasse os limites, que vá além do esperado, que transgrida no âmbito da criação.

O personagem fruto do autor-criador é autor de si mesma. No MMORPG, este personagem pode ser percebido quando não reconhecemos a voz do autor ou jogador, por meio de suas marcas lingüísticas. Não há mais vínculo. O personagem é autônomo e visto em sua completude. Apresenta características que não refletem os valores de seu criador, mas sim, seus próprios valores morais, éticos, estéticos, religiosos, dentre outros. Poderíamos citar alguns exemplos de personagens da literatura universal que alcançaram sua completude, como: Sherlock Holmes, Rei Arthur, Robin Hood, Conde Drácula, Frankenstein,e outros. E da literatura brasileira, poderíamos destacar personagens, como: Macunaíma, Cuca, Policarpo Quaresma, Dom Casmurro e Capitu, entre vários.

Em alguns exemplos, o leitor não se lembra do autor, mas reconhece sem problemas o personagem. Há casos em que o leitor crê na sua existência, como ocorre com Sherlock Holmes, cuja casa, descrita nas obras de Sir Arthur Conan Doyle, foi transformada em museu, e recebe visitantes de todos os lugares do mundo. Este caso é interessante, pois diversos estudiosos da literatura questionam se realmente o autor é Sir Arthur Conan Doyle. Quão grande é a autonomia do personagem, que se desvinculou por completo de seu autor.

Bakhtin (2003, p. 10) define o autor como "o agente da unidade tensamente ativa do todo acabado, do todo do personagem e do todo da obra, e este é transgrediente à cada elemento particular desta”. O autor não determinará a estrutura de seu personagem imediatamente. É necessário que o autor-criador compreenda a visão do personagem para estruturá-lo e para que o resultado de sua produção criativa seja completo. O autor deve considerar a imagem, os aspectos sociais do personagem, os elementos semânticos que estarão presentes em sua obra, dentre tantos outros itens que compõem a estruturação de um personagem como um todo.

O reconhecimento dessa diferença entre o relato biográfico e a capacidade criativa possibilitará ao autor a construção de uma resposta total e única em sua obra, e isso incidirá na estruturação de um personagem completo. Ao perceber que o personagem completo não deve ser a continuação da voz do autor, mas sim, uma criação desvinculada de seu criador, com idéias, sentido, vivências e valores próprios, o autor ou jogador terá a possibilidade de criar um ser autônomo, visto em seu todo, como uma resposta única às manifestações anteriores. Neste momento, o autor-criador, ou neste caso, ou jogador-criador, alcançará a completude do personagem no plano estético, em sua relação com a arte literária.

\section{Bronckart}

Sob a ótica do Interacionismo Sócio-Discursivo (ISD) proposto por Bronckart, a interação detectada na espécie humana é resultado de um modo de comunicação particular, que é a linguagem e essa atividade de linguagem organiza-se em discursos ou em textos (Bronckart, 1999, p. 35).

Também é conveniente lembrar que é por meio dos textos ou discursos que se constroem mundos representados, propostos por Habermas e utilizados por Bronckart, como uma das vertentes teóricas para esclarecer o ISD. E esses mundos representados são: o mundo objetivo, relacionado ao mundo físico; o mundo social, onde ocorre a interação entre o sujeito e o meio; e o mundo subjetivo, referente ao sujeito. Estes mundos 
representados definem a situação da ação de linguagem, e podem exercer influência na produção dos textos.

O texto, de uma maneira geral, pode ser definido como "toda e qualquer produção de linguagem situada, oral ou escrita" (Bronckart, 1999, p. 71) e compõe o rol das ações humanas em suas dimensões sociais e discursivas. Todos os textos têm algo em comum: apresentam uma relação de interdependência com o contexto em que foram produzidos. Cada texto foi elaborado a sua maneira, mas sempre obedecendo a uma coerência interna referente àquela espécie de texto. Segundo Bronckart, os contextos sociais são diversos e evolutivos no decorrer da história e foram elaborados diferentes "modos de fazer" textos, ou diferentes "espécies de textos" (1999, p. 72).

O termo "espécie de texto" é usado de maneira provisória por Bronckart, pois ainda há uma vagueza em sua definição. O autor afirma apenas que a noção de "espécie de texto" designa "todo conjunto de textos que apresentem características comuns" (1999, p. 72), como: os romances que surgiram em uma determinada época, ou artigos científicos de um dado período que surgiram por motivações sociais; ou ainda, textos comerciais ou publicitários que surgiram de novas circunstâncias de comunicação; ou também, os artigos de jornal, as entrevistas por rádio, ou notícias via rede mundial de computadores (Internet) que apareceram com os novos adventos da comunicação. E neste caso, enquadramos o MMORPG, discutido neste trabalho, propondo-o como hipergênero ou, seguindo a linha do autor, um novo gênero de texto, o texto digital, em seus desdobramentos, como emails, blogs, chats, homepages, games e outros.

Por causa da diversidade de espécies de textos, houve a necessidade de classificálos, daí o surgimento da proposta bakhtiniana de gêneros de discurso, ou gênero de texto como é usado por Bronckart. O autor atribui a enorme dificuldade em classificar um gênero à diversidade de critérios existentes para defini-lo, como por exemplo, critérios relacionados a: a atividade humana implicada (gênero literário, científico, jornalístico, etc.); o efeito comunicativo visado (gênero épico, lírico, narrativo, etc.); o tamanho ou à natureza do suporte utilizado (romance, artigo de jornal, reportagem, etc.); o conteúdo temático abordado (ficção científica, romance policial, receita culinária, etc.) (Bronckart, 1999, p. 74). Além disso, ainda há o problema do desaparecimento, do reaparecimento, do surgimento ou da modificação dos gêneros que impedem o estabelecimento de fronteiras para classificá-los. Enfim, os gêneros "não podem ser objetos de uma classificação definitiva" (Bronckart, 1999, p. 108).

No entanto, dada a necessidade de classificar o MMORPG para possibilitar uma melhor análise do texto trabalhado, adotaremos a proposta de Haag et al (2005), no artigo, $O$ jogo digital como um "hipergênero", que sugere adotar-se o jogo digital como hipergênero. O MMORPG, visto como um jogo digital apresenta peculiaridades que ainda não foram abordados pelo ISD. E a noção de hipergênero abarca características presentes neste jogo realizado no âmbito digital.

Neste momento, discorreremos sobre alguns elementos que são contemplados pelo ISD e o ponto que nos interessa refere-se ao responsável pela produção do texto, o autor.

No que diz respeito ao contexto de produção do texto, Bronckart (1999, p. 95) destaca que "é necessário reconhecer que a instância responsável pela produção de um texto é uma entidade única, que deve ser definida, tanto do ponto de vista físico, quanto do ponto de vista sociosubjetivo". E esta instância responsável pelo texto é o autor, a que Bronckart prefere denominar como agente-produtor. 
$\mathrm{Na}$ busca em estabelecer a coerência do texto, o autor ou agente-produtor do texto, apresenta um posicionamento enunciativo, que atribui uma voz ao texto, que pode ser ou não a do agente-produtor. Conforme Bronckart (1999, p. 130), essas vozes podem ser divididas em três subconjuntos: a voz do autor empírico, que corresponde à própria voz do autor; as vozes sociais, isto é, as vozes de outras pessoas ou de instituições humanas exteriores ao conteúdo temático do texto; e as vozes de personagens, isto é, as vozes de pessoas ou de instituições diretamente implicadas no percurso temático. Por este motivo, há vários mundos discursivos em um texto.

Bronckart classifica os mundos representados, postulados por Habermas, em que ocorre a atividade humana, como mundo ordinário. E os mundos em que ocorre a atividade de linguagem, como mundos discursivos. $\mathrm{O}$ autor considera dois subconjuntos que operam no mundo discursivo. O primeiro expõe a relação existente entre o conteúdo temático de um texto e as representações presentes no mundo ordinário, e o segundo explicita a relação do autor, ou agente-produtor, e a sua posição de espaço e tempo, além dos parâmetros de ação de linguagem percebidos no texto. Bronckart (1999, p. 152) os denomina, respectivamente, como: ordem do expor e ordem do narrar.

$\mathrm{Na}$ ordem do expor, o autor, ou agente-produtor, ou no caso em questão, ou jogador, apresenta um texto do mundo real. Se o receptor perceber o uso de elementos ficcionais, o texto perderá a credibilidade, pois estes elementos proporcionarão um aspecto falso ao texto. Poderíamos dizer que o autor-pessoa de Bakhtin se insere na ordem do narrar. Já na ordem do narrar, os elementos ficcionais são totalmente aceitáveis e recomendáveis, pois o autor do texto pode situar-se em outro espaço e tempo, que não seja o real, mas ainda sim deve transportar características do mundo ordinário para que o receptor o interprete. Quanto à perspectiva backhtiniana, poderíamos enquadrar o autor-criador na ordem do narrar de Bronckart.

No que tange ao MMORPG, o autor se inscreve na ordem do jogar, conforme Haag et al (2005). Como um hipergênero, as possibilidades do autor que se constitui na ordem do jogar se expande, pois além de contar com os elementos ficcionais da ordem do narrar, pode contar também com os diversos recursos visuais e sonoros do ambiente digital para construir o seu texto. Estes recursos contribuirão no processo de criação do autor, ou jogador, ou usando um termo mais amplo e condizente com a situação, do cidadão, que terá em mãos outras armas para desenvolver suas competências e habilidades que o favoreçam em sua prática social.

\section{Quadro comparativo}

\begin{tabular}{|c|c|c|}
\hline $\begin{array}{c}\text { Autor } \\
\text { (Bakhtin) }\end{array}$ & $\begin{array}{c}\text { Mundo discursivo } \\
\text { (Bronckart) }\end{array}$ & $\begin{array}{c}\text { Personagem } \\
\text { (Bakhtin) }\end{array}$ \\
\hline Autor-pessoa & Ordem do expor & Personagem incompleto \\
\hline Autor-criador & Ordem do narrar & Personagem completo \\
\hline
\end{tabular}

\section{Considerações finais}

A necessidade de inserção em uma sociedade, cuja informática se faz tão presente, promove o desenvolvimento de projetos nas escolas e pesquisas no âmbito acadêmico, que utilizam os recursos tecnológicos disponíveis nas instituições educacionais como meio para que o próprio aluno desenvolva suas habilidades e competências para participar como agente de sua prática social. 
A proposta apresentada é uma alternativa para que o professor observe em seus alunos como se constitui o autor no processo de construção de seu personagem. Com base nas teorias visitadas, o professor terá em mãos um suporte para orientá-lo na análise do personagem e de seu respectivo autor. Cabe ao professor apresentar aos alunos o tipo de personagem que espera encontrar no MMORPG trabalhado em sala de aula.

Ao utilizar o suporte teórico no ambiente digital, o professor deve observar as possibilidades que a tecnologia oferece ao aluno, ou ao autor, durante o processo de constituição de seu personagem. Recursos como a imagem, os efeitos sonoros que podem ser percebidos, em seu conjunto, somente no ambiente digital, devem ser considerados na análise do personagem, sob a perspectiva bakhtiniana, presente no mundo discursivo proposto por Bronckart.

A partir da apresentação da constituição do personagem e de seu respectivo autor no ambiente do MMORPG, pretendemos que o professor reflita sobre suas práticas em sala de aula e perceba como as novas tecnologias devem estar presentes no contexto educacional. O professor deve enxergar os recursos digitais como uma ferramenta necessária no contexto escolar, pois promove a instantaneidade do acesso à informação, a interatividade promovida por programas que oferecem diferentes tipos de ambiente de aprendizagem, e o MMORPG, em especial, promove a imersão do autor, ou jogador, no ambiente em que o jogo se constrói.

A escola deve compreender a inserção do adolescente no ambiente digital das novas tecnologias da informação como uma prática social, pois sua utilização implica a participação ativa em uma sociedade, cujos sistemas tecnológicos passaram a moldar novas formas organização. E tão importante quanto inserir esse adolescente nessa realidade digital, é saber como usar essa vivência de uma maneira produtiva, crítica, agradável e teoricamente abalizada.

\section{Notas}

${ }^{1}$ TICs ( tecnologias de informação e comunicação) serão,também, chamadas neste artigo de novas tecnologias

\section{REFERÊNCIAS BIBLIOGRÁFICAS:}

AMARAL, Ricardo. O RPG como instrumento pedagógico. Arscientia, São Paulo, mar. $2006 . \quad$ Disponível em: <http://www.arscientia.com.br/materia/ver_materia.php?id_materia=149>. Acesso em: mai. 2007.

BAKHTIN, Mikhail. O autor e a Personagem. In: Estética da Criação Verbal. São Paulo: Martins Fontes, 2003.

BRONCKART, Jean-Paul. Atividade de linguagem, textos e discursos. Por um interacionismo sócio-discursivo. São Paulo: EDUC, 1999.

DAVID, Wilson. Anotações sobre Bakhtin. Unicamp, Campinas, dez. 2003. Disponível em: <http://www.unicamp.br/iel/site/alunos/publicacoes/textos/a00006.htm>. Acesso em: mai. 2007.

DUTRA, Ítalo Modesto e LACERDA, Rosália Procasko. Tecnologias na escola: algumas experiências e possibilidades. Renote, Porto Alegre, v. 1, n. 1, fev. 2003. Disponível em: <http://www.cinted.ufrgs.br/renote/fev2003/artigos/italo_tecnologias.pdf>. Acesso em: mai. 2007. 


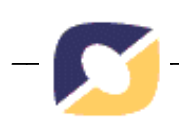

FRAGA, Dinorá e PEDROSO, Felipe Silveira. Jogo de RPG no ensino e aprendizagem de narrativas não-lineares. Renote, Porto Alegre, v. 4, n. 2, dez. 2006. Disponível em: $<$ http://www.cinted.ufrgs.br/renote/dez2006/artigosrenote/25174.pdf>. Acesso em: mai. 2007.

FRANCO, Jorge Ferreira e LOPES, Roseli de Deus. Novas Tecnologias em Ambientes de Aprendizagem; Estimulando o Aprender a Aprender, Transformando o Currículo e Ações. Renote, Porto Alegre, v. 2, n. 1, mar. 2004. Disponível em: $<$ http://www.cinted.ufrgs.br/renote/mar2004/artigos/39-novastecnologias.pdf>. Acesso em: mai. 2007.

GARCIA, Fabiane Maia. Tecnologia e educação: relações históricas, locais e mundializadas. Renote, Porto Alegre, v. 3, n. 1, mai. 2005. Disponível em: $<$ http://www.cinted.ufrgs.br/renote/maio2005/artigos/a52_tecnologiaeducacao.pdf >. Acesso em: mai. 2007.

HAAG, Cassiano Ricardo; FRAGA, Dinorá; SILVA, Leandro Coimbra da; LACERDA, Geovane Dantas. O jogo digital como um "hipergênero". Revista Eletrônica de Divulgação Científica em Língua Portuguesa, Lingüística e Literatura Letra Magna. Ano 02, n. 3, $2^{\circ}$ semestre de 2004. Disponível em: <http://www.letramagna.com/CassianoRHaag.pdf>. Acesso em: 30 jun 2007.

LOPES, Laura Maria Coutinho; KLIMICK, Carlos; CASANOVA, Marco Antônio. Relato de uma experiência de Sistema Híbrido no Ensino Fundamental: Projeto Aulativa. Revista Brasileira de Aprendizagem Aberta e à Distância, jan. 2003. Disponível em: < http://www.abed.org.br/publique/cgi/cgilua.exe/sys/start.htm?infoid=617\&sid=48\&UserAc tiveTemplate=1por $>$. Acesso em: mai. 2007.

MACHADO, Mário Lúcio Mesquita; SOUZA, Diego Gomes; SOUZA, João Artur de; DANDOLINI, Gertrudes; SILVEIRA, Ricardo Azambuja. RPG: Uma abordagem empregando sistemas multiagentes. Renote, Porto Alegre, v. 2, n. 1, mar. 2004. Disponível em: <http://www.cinted.ufrgs.br/renote/mar2004/artigos/19-rpg_umaabordagem.pdf>. Acesso em: mai. 2007.

MOLINA, William Fernandes. Análise das características narrativas e do ambiente digital dos jogos em rede: um estudo de caso do jogo Priston Tale. 2007. Dissertação (Mestrado em Ciências da Linguagem) - Universidade do Sul de Santa Catarina, Florianópolis, 2007. Disponível em: <http://busca.unisul.br/pdf/85977_William.pdf>. Acesso em: 05 jul 2007.

RECHDAN, Maria Letícia de Almeida. Dialogismo ou Polifonia. Revista Ciências Humanas, Taubaté, v. 9, n. 1, $1^{\text {o }}$ semestre de 2003. Disponível em: $<$ http://www.unitau.br/scripts/prppg/humanas/download/dialogismo-N1-2003.pdf>. Acesso em: mai. 2007. 